\title{
A mutation of Aspergillus niger for hyper-production of citric acid from corn meal hydrolysate in a bioreactor"
}

\author{
Wei HU ${ }^{1,2,3}$, Jing LIU ${ }^{1,3}$, Ji-hong CHEN ${ }^{\$ 1,3}$, Shu-yang WANG ${ }^{1,3}$, Dong LU $U^{1,3}$, \\ Qing-hua WU ${ }^{1,3}$, Wen-jian $\mathrm{LI}^{\dagger+1,3}$ \\ ('Institute of Modern Physics, Chinese Academy of Sciences, Lanzhou 730000, China) \\ ( ${ }^{2}$ University of Chinese Academy of Sciences, Beijing 100049, China) \\ ( ${ }^{3}$ Key laboratory of Microbial Resources Exploition and Application, Lanzhou 730000, China) \\ †E-mail: chjh@impcas.ac.cn; wjli@impcas.ac.cn \\ Received May 8, 2014; Revision accepted Aug. 4, 2014; Crosschecked Oct. 11, 2014
}

\begin{abstract}
The properties of the screened mutants for hyper-production of citric acid induced by carbon $\left({ }^{12} \mathrm{C}^{6+}\right)$ ion beams and X-ray irradiation were investigated in our current study. Among these mutants, mutant $\mathrm{H} 4002$ screened from ${ }^{12} \mathrm{C}^{6+}$ ion irradiation had a higher yield of citric acid production than the parental strain in a $250-\mathrm{ml}$ shaking flash. These expanded submerged experiments in a bioreactor were also carried out for mutant $\mathrm{H} 4002$. The results showed that (177.7-196.0) $\mathrm{g} / \mathrm{L}$ citric acid was accumulated by $\mathrm{H} 4002$ through exploiting corn meal hydrolysate (containing initial 200.0-235.7 g/L sugar) with the productivity of $(2.96-3.27) \mathrm{g} /(\mathrm{L} \cdot \mathrm{h})$. This was especially true when the initial sugar concentration was $210 \mathrm{~g} / \mathrm{L}$, and the best economical citric acid production reached $(187.5 \pm 0.7) \mathrm{g} / \mathrm{L}$ with a productivity of $3.13 \mathrm{~g} /(\mathrm{L} \cdot \mathrm{h})$. It was observed that mutant $\mathrm{H} 4002$ can utilize low-cost corn meal as a feedstock to efficiently produce citric acid. These results imply that the $\mathrm{H} 4002$ strain has the industrial production potentiality for citric acid and offers strong competition for the citric acid industry.
\end{abstract}

Key words: Mutation, Citric acid, Corn meal hydrolysate, Aspergillus niger doi:10.1631/jzus.B1400132 Document code: A CLC number: Q819

\section{Introduction}

Citric acid fermentation is one of the largest biotechnological industries (Ikram-ul et al., 2004), and it has been proven that Aspergillus niger is the most effective strain for citric acid production by fermentation of carbohydrates (Lesniak et al., 2002) through secreting large amounts of enzymes into the environment for degrading carbon sources into small sugar molecules that are then used to serve as nutrients (de Bekker et al., 2011). According to various estimates, citric acids produced through fermentation

\footnotetext{
ॠCorresponding authors

* Project supported by the Agriculture Science and Technology Achievement Transformation Fund of Science and Technology Ministry of China (Nos. 2013GB24910680 and 2012GB24910647)

(C) Zhejiang University and Springer-Verlag Berlin Heidelberg 2014
}

are $1.7 \times 10^{6}$ t/a (Dhillon et al., 2011), but the industrial demands for citric acid are still increasing. Presently, China occupies a large market share in the citric acid industry all over the world, and the yield reached $0.94 \times 10^{6}$ t/a (Yang et al., 2013), but conventional citric acid fermentation biotechnology in China is not yet economically competitive. For instance, in 2008, the best citric acid production level of Chinese manufacturers was $146.9 \mathrm{~g} / \mathrm{L}$ and the best productivity was $2.7 \mathrm{~g} /(\mathrm{L} \cdot \mathrm{h})$ (Gao and Yang, 2010). A patent with citric acid concentration of $173 \mathrm{~g} / \mathrm{L}$ and productivity of $2.66 \mathrm{~g} /(\mathrm{L} \cdot \mathrm{h})$ was also reported by Zhang et al. (2013). Both are much lower than the advanced levels in the rest of the world (Hu et al., 2014).

High yield depends mainly on the strains used and the industrial production of citric acid by fermentation using cheap raw material is helpful to the 
economic development of a country (Majumder et al., 2009). Aiming to obtain high yields at a production scale level, a possible strategy is to improve the properties of the microbial production strain (Hu et al. 2014). Presently, as a novel mutagenesis technique, heavy ion irradiation has been referred to as a means of breeding new mutants of different microorganism, such as ${ }^{12} \mathrm{C}^{6+}$ ion irradiation (Wang et al., 2009; Zhou et al., 2013). When compared with traditional physical or chemical mutagenic agents, such as X-rays or $\gamma$-rays, heavy ion beams induce a higher mutation rate and create a wide range of mutation types due to their higher linear energy transfer (LET) and greater relative biological effect (RBE) (Du et al., 2014). Progress has also been made in heavy ion mutation breeding of Clostridium tyrobutyricum, microalga Desmodesmus sp., etc. (Hu et al., 2013; Zhou et al., 2014). However, few reports concerning breeding of A. niger by heavy ion beams uniting corn meal hydrolysate as the feedstock in a bioreactor for hyper citric acid have been published (Hu et al., 2014).

In this study, we successfully screened a high yield strain of $A$. niger for citric acid by ${ }^{12} \mathrm{C}^{6+}$ ion irradiation. In addition, the kinetics of citric acid production and sugar consumption in a bioreactor by this strain under different sugar concentrations was also studied.

\section{Materials and methods}

\subsection{Organism and culture maintenance}

A parental strain, preserved at the biophysics lab in the Institute of Modern Physics, Chinese Academy of Sciences, was maintained on potato-dextrose agar slants and stored at $4{ }^{\circ} \mathrm{C}$ in a refrigerator.

\subsection{Isolation of mutants}

H4002, H1, H3, H4, and H5 were obtained after carbon ion irradiation. XHW2 and XHW3 were obtained after X-ray irradiation. The large diameter of transparent halos and morphology by a single colony on agar plates were employed for preliminary screening mutants. The agar plate contained $200 \mathrm{~g} / \mathrm{L}$ potato juice, $20 \mathrm{~g} / \mathrm{L}$ sucrose, $20 \mathrm{~g} / \mathrm{L}$ agar, and $0.2 \mathrm{~g} / \mathrm{L}$ bromocresol green. The fermentation medium was prepared with $0.25 \mathrm{~g} / \mathrm{ml}$ corn meals, which were hydrolyzed by $\alpha$-amylase at $95-98{ }^{\circ} \mathrm{C}$ for $30 \mathrm{~min}$ in a
10-L bioreactor. After being filtered, the supernatant hydrolysate was obtained with an initial $\mathrm{pH} 5.15$. Corn meals were obtained from smashing corn grains. The medium used in all the studies of citric acid fermentation in the shake flash $(250 \mathrm{ml})$ contained corn meal hydrolysate with sugar concentration $166.2 \mathrm{~g} / \mathrm{L}$ and $5 \mathrm{~g} / \mathrm{L}$ soybean cake. The medium was then autoclaved at $115^{\circ} \mathrm{C}$ for $30 \mathrm{~min}$.

\subsection{Conversion of corn meal hydrolysate into cit- ric acid by mutant $\mathrm{H} 4002$}

Fermentation was carried out in a 50-L stirred tank reactor. The fermentation medium was prepared with the following source of carbohydrates. Corn meals $(0.25 \mathrm{~g} / \mathrm{ml})$ were hydrolyzed by $\alpha$-amylase at $60-72{ }^{\circ} \mathrm{C}$ for $30 \mathrm{~min}$ and $95-98{ }^{\circ} \mathrm{C}$ for about $10 \mathrm{~min}$ in the 50 -L bioreactor. After centrifugal filtration, liquefying supernatant was obtained and diluted with tap water to the desired sugar concentration. The medium was then autoclaved at $118^{\circ} \mathrm{C}$ for $30 \mathrm{~min}$.

\subsection{Analytical methods}

The concentration of citric acid in culture filtrate was measured by titration with $0.1429 \mathrm{~mol} / \mathrm{L}$ sodium hydroxide using $0.5 \%$ phenolphthalein as an indicator. Total sugar was hydrolyzed by $6 \mathrm{~mol} / \mathrm{L}$ vitriol at boiling temperature for $10 \mathrm{~min}$ into glucose and fructose, and then analyzed by a Fehling reagent (Jin and Cen, 2004). For the calculation of dry cell mass, the mycelium was thoroughly washed with tap water and dried to a constant weight after centrifugation of $5 \mathrm{ml}$ fermentation broth at $4000 \mathrm{r} / \mathrm{min}$ for $5 \mathrm{~min}$. All the experiments were repeated two or three times.

\section{Results and discussion}

\subsection{Isolation of mutants for citric acid production induced by ${ }^{12} \mathrm{C}^{6+}$ ion and $\mathrm{X}$-ray irradiations}

In the present study, numerous mutants induced by ${ }^{12} \mathrm{C}^{6+}$ ion and $\mathrm{X}$-ray irradiations were primarily screened on the selective plate medium. Compared with the parental strain, the citric acid production by the screened strains H4002 and XHW3 was greatly improved in terms of the final citric acid concentration and productivity (Fig. 1). The parental strain and both mutants H4002 and XHW3 could synthesize (70.25 \pm 5.30$),(76.55 \pm 1.48)$, and $(72.80 \pm 0.56) \mathrm{g} / \mathrm{L}$ 
citric acids, respectively, and produced (34.62 \pm 0.71$)$, $(31.62 \pm 0.31)$, and $(32.17 \pm 1.49) \mathrm{g} / \mathrm{L}$ dry biomass. The increase in citric acid production was substantial for the H4002 and XHW3 strains, especially H4002, which showed the highest capacity in citric acid production with an increase of $8.9 \%$.

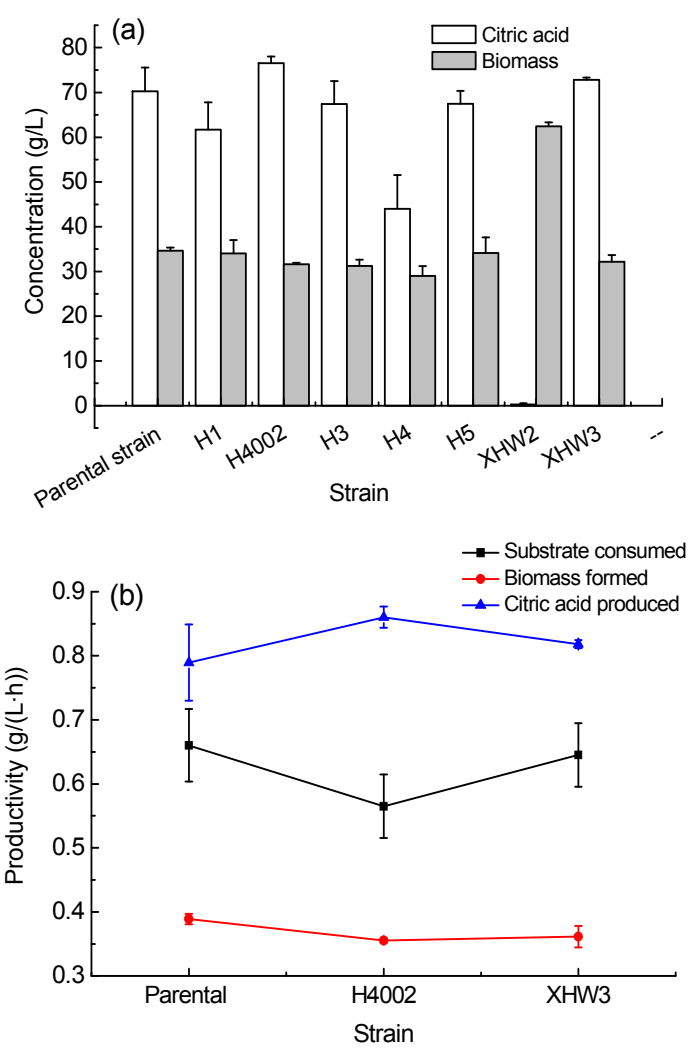

Fig. 1 Citric acid productions of the parental strain and its mutant derivatives induced by ${ }^{12} \mathrm{C}^{6+}$ ion and $\mathrm{X}$-ray irradiations when grown in corn meal hydrolysate

(a) Citric acid and biomass concentrations. (b) Kinetic parameters for citric acid production. Culture conditions: temperature $(36.8 \pm 0.4){ }^{\circ} \mathrm{C}$, initial $\mathrm{pH} \mathrm{5.15}$, fermentation time $89 \mathrm{~h}$. Data are expressed as mean \pm standard deviation (SD), $n=3$ or 4

Specific productivities $(\mathrm{g} /(\mathrm{L} \cdot \mathrm{h}))$, such as citric acid produced, biomass formed, and substrate consumed, are shown in Fig. 1b. Mutant H4002 exhibited the maximum production improvement (increased by $8.97 \%$ ), low substrate consumption (decreased by $13.9 \%$ ), and low biomass production (decreased by $8.66 \%)$ over the parental strain. In another word, H4002 utilized lower sugar consumption to produce more citric acids, which was helpful for material utilization. Consequently, it was proven that the mu- tant $\mathrm{H} 4002$ showed a high citric acid production and productivity through the shaking flash culture.

\subsection{Conversion of corn meal hydrolysate into cit- ric acid by mutant $\mathrm{H} 4002$}

To produce citric acid on a large scale for industrial applications, a 50-L bioreactor was implemented to produce citric acid by mutant $\mathrm{H} 4002$ due to its good physical parameters, such as dissolved oxygen. Meanwhile, the type and concentration of the carbon source are probably the most crucial parameters for successful citric acid production (Karaffa and Kubicek, 2003).

Fig. 2 shows the kinetic parameters for citric acid production at different concentrations of corn meal hydrolysates as a carbon source by mutant H4002 in a 50-L agitator bioreactor. Under the optimized culture condition (data not shown), when the initial sugar concentration increased from $(200 \pm 0.0)$ to $(235.7 \pm 2.4) \mathrm{g} / \mathrm{L}$, the produced citric acid also increased from $(177.7 \pm 3)$ to $(196 \pm 0.0) \mathrm{g} / \mathrm{L}$ after $60 \mathrm{~h}$ fermentation (Fig. 2b), and the citric acid productivity was 2.96 and $3.27 \mathrm{~g} /(\mathrm{L} \cdot \mathrm{h}$ ) (Fig. 2c), the final sugar concentration decreased to $(26.7 \pm 0.7)$ and $(36.9 \pm 0.8) \mathrm{g} / \mathrm{L}$ (Fig. 2a), and the conversion rate was $88.85 \%$ and $83.1 \%$ (Fig. 2c), respectively. Especially, when the initial sugar concentration reached $210 \mathrm{~g} / \mathrm{L}$, the mutant $\mathrm{H} 4002$ exhibited the best citric acid accumulation of $(187.5 \pm 0.7) \mathrm{g} / \mathrm{L}$, with a high productivity of $3.13 \mathrm{~g} /(\mathrm{L} \cdot \mathrm{h})$, a high conversion rate of $89.25 \%$, and a low residual sugar concentration of $(26.0 \pm 0.4) \mathrm{g} / \mathrm{L}$. Furthermore, during the whole fermentation process, round and compact pellets were being observed all the time, which improved the properties of the process and enhanced the citric acid production (Pera and Callieri, 1997; Ikram-ul et al., 2001).

An important issue for citric acid production is whether the process is economical. A low cost of feedstock is a very important factor in establishing a cost-effective technology (Mojovic et al., 2006). Recently, in order to increase the efficiency of citric acid production, different mutants and feedstock have been studied, but the productivity achieved was not high enough for the competitive economical environment in an industrial operation. Compared with the best production levels of $146.9 \mathrm{~g} / \mathrm{L}$ reported by Gao and Yang (2010) and a patent with citric acid concentration of $173 \mathrm{~g} / \mathrm{L}$ and productivity of $2.66 \mathrm{~g} /(\mathrm{L} \cdot \mathrm{h})$ 
reported by Zhang et al. (2013), there are significant increases in both citric acid concentration and productivity by mutant $\mathrm{H} 4002$. Consequently, these findings suggest that the mutant H4002 strain possesses enhanced the efficiency for citric acid production from corn meal hydrolysate metabolism.
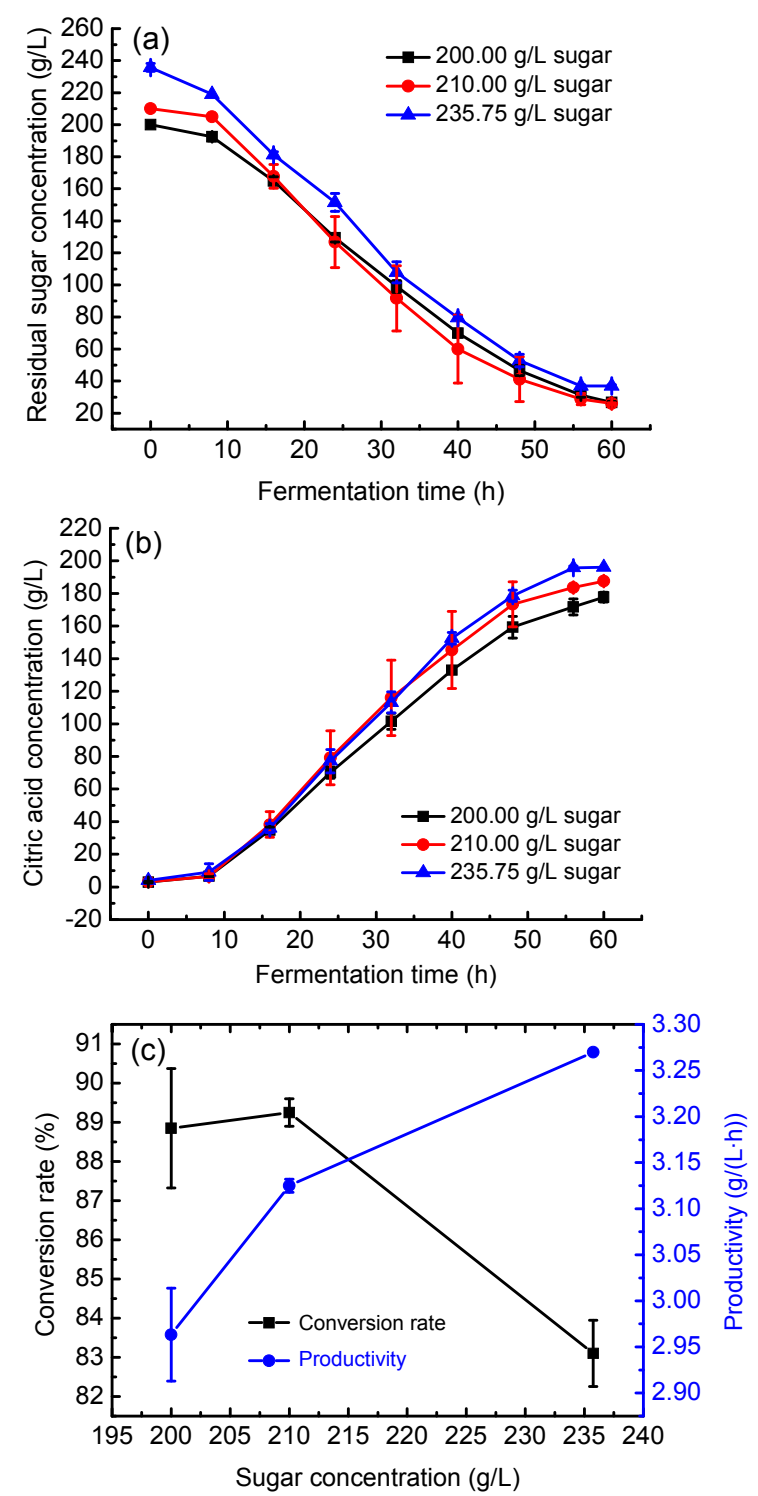

Fig. 2 Kinetics of citric acid production converted from different concentrations of corn meal hydrolysate by mutant $\mathrm{H} 4002$ in a 50- $\mathrm{L}$ bioreactor

(a) Sugar consumed during fermentation; (b) Citric acid produced during fermentation; (c) Conversion rates and productivity. Data are expressed as mean \pm standard deviation (SD), $n=3$

Although the molecular mechanisms of biological action of ion irradiation are not yet understood
(Yang et al., 2007), as a novel irradiation technique, it deserves further attention due to its high LET and RBE, which can result in a wider mutation spectrum and higher ratio of mutation. Further work will be carried out to determine any additional benefits from changing the key genes in mutant H4002, compared with the parental strain. The improvement of the substrate consumption rate in the H4002 strain will also be studied.

\section{Conclusions}

To obtain mutants for hyper citric acid production, we used the accelerated carbon ions and X-rays as a tool to induce mutagenesis of $A$. niger. After the isolation of the irradiated $A$. niger, we successfully obtained a mutant, named H4002, with enhanced citric acid production, which was screened from carbon ion irradiation. Under the optimized culture condition in a bioreactor, H4002 exhibited (187.5 \pm 0.7$) \mathrm{g} / \mathrm{L}$ citric acid accumulation and it implied that the H4002 strain has the industrial production potentiality for citric acid and offers a strong competition for the citric acid industry.

\section{Acknowledgements}

The authors are grateful to all the staff of the Heavy Ion Research Facility in Lanzhou (HIRFL), China, for providing the carbon beams.

\section{Compliance with ethics guidelines}

Wei HU, Jing LIU, Ji-hong CHEN, Shu-yang WANG, Dong LU, Qing-hua WU, and Wen-jian LI declare that they have no conflict of interest.

This article does not contain any studies with human or animal subjects performed by any of the authors.

\section{References}

de Bekker, C., van Veluw, G.J., Vinck, A., et al., 2011. Heterogeneity of Aspergillus niger microcolonies in liquid shaken cultures. Appl. Environ. Microbiol., 77(4):12631267. [doi:10.1128/AEM.02134-10]

Dhillon, G.S., Brar, S.K., Verma, M., et al., 2011. Recent advances in citric acid bio-production and recovery. Food Bioprocess Technol., 4(4):505-529. [doi:10.1007/s11947010-0399-0]

Du, Y., Li, W.J., Yu, L.X., et al., 2014. Mutagenic effects of carbon-ion irradiation on dry Arabidopsis thaliana seeds. Mutat. Res. Genet. Toxicol. Environ. Mutagen., 759(1): 28-36. [doi:10.1016/j.mrgentox.2013.07.018] 
Gao, N.F., Yang, F., 2010. Innovation and development of the citric acid fermentation industry in our country. China Brewing, 7:1-6 (in Chinese).

Hu, G.R., Fan, Y., Zhang, L., et al., 2013. Enhanced lipid productivity and photosynthsis efficiency in a Desmodesmus sp. mutant induced by heavy carbon ions. PLoS $O N E$, 8(4):e60700. [doi:10.1371/journal.pone.0060700]

Hu, W., Chen, J.H., Li, W.J., et al., 2014. Mutant breeding of Aspergillus niger irradiated by ${ }^{12} \mathrm{C}^{6+}$ for hyper citric acid. Nucl. Sci. Tech., 25(2):1-4. [doi:10.13538/j.1001-8042/ nst.25.020302]

Ikram-ul, H., Khurshid, S., Ali, S., et al., 2001. Mutation of Aspergillus niger for hyper-production of citric acid from black strap molasses. World J. Microbiol. Biotechnol., 17(1):35-37. [doi:10.1023/A:1016625130070]

Ikram-ul, H., Ali, S., Qadeer, M.A., et al., 2004. Citric acid production by selected mutants of Aspergillus niger from cane molasses. Bioresource Technol., 93(2):125-130. [doi:10.1016/j.biortech.2003.10.018]

Jin, Z.H., Cen, P.L., 2004. Improved production of spiramycin by mutant Streptomyces ambofaciens. J. Zhejiang Univ. Sci., 5(6):689-695. [doi:10.1631/jzus.2004.0689]

Karaffa, L., Kubicek, C.P., 2003. Aspergillus niger citric acid accumulation: do we understand this well working black box? Appl. Microbiol. Biotechnol., 61(3):189-196. [doi:10. 1007/s00253-002-1201-7]

Lesniak, W., Pietkiewicz, J., Podgorski, W., 2002. Citric acid fermentation from starch and dextrose syrups by a trace metal resistant mutant of Aspergillus niger. Biotechnol. Lett., 24(13):1065-1067. [doi:10.1023/A:1016030513270]

Majumder, L., Khalil, M.I., Munshi, M.K., et al., 2009. Gamma-ray induced mutants 14/20 and 79/20 of Aspergillus niger increase citric acid production from molasses and pumpkin. Afr. J. Basic Appl. Sci., 1(1-2):26-30.
Mojovic, L., Nikolic, S., Rakin, M., et al., 2006. Production of bioethanol from corn meal hydrolyzates. Fuel, 85(12-13): 1750-1755. [doi:10.1016/j.fuel.2006.01.018]

Pera, L.M., Callieri, D.A., 1997. Influence of calcium on fungal growth, hyphal morphology and citric acid production in Aspergillus niger. Folia Microbiol., 42(6): 551-556. [doi:10.1007/BF02815463]

Wang, J.F., Li, R.M., Lu, D., et al., 2009. A quick isolation method for mutants with high lipid yield in oleaginous yeast. World J. Microbiol. Biotechnol., 25(5):921-925. [doi:10.1007/s11274-009-9960-2]

Yang, Y., Wang, D.P., Gao, N.F., 2013. Changes of $\alpha$-glucosidase and glucoamylase from Aspergillus niger in citric acid fermentation. China Brewing, 32(1):22-24 (in Chinese).

Yang, Y.N., Ren, N., Xue, J.M., et al., 2007. Mutation effect of $\mathrm{MeV}$ protons on bioflocculant bacteria Bacillus cereus. Nucl. Instrum. Methods Phys. Res. B, 262(2):220-224. [doi:10.1016/j.nimb.2007.05.016]

Zhang, J.H., Zhou, Y., Zhong, H., et al., 2013. A method of both application by Aspergillus niger and the preparation of citric acid. China Patent CN 102399702 B (in Chinese).

Zhou, X., Xin, Z.J., Lu, X.H., et al., 2013. High efficiency degradation crude oil by a novel mutant irradiated from Dietzia strain by ${ }^{12} \mathrm{C}^{6+}$ heavy ion using response surface methodology. Bioresource Technol., 137:386-393. [doi:10. 1016/j.biortech.2013.03.097]

Zhou, X., Lu, X.H., Li, X.H., et al., 2014. Radiation induces acid tolerance of Clostridium tyrobutyricum and enhances bioproduction of butyric acid through a metabolic switch. Biotechnol. Biofuels, 7(1):22. [doi:10.1186/1754-68347-22]

\section{中文概要：}

\section{本文题目: 高产柠檬酸突变菌株以玉米粉为原料的生物反应器扩大生产研究}

A mutation of Aspergillus niger for hyper-production of citric acid from corn meal hydrolysate in a bioreactor

研究目的: 研究高产黑曲霉突变菌株以玉米粉为原料的生物反应器扩大发酵, 以期获得适合于工业化生 产柠檬酸的发酵工艺。

创新要点: 以玉米粉为原料, 系统地研究了篮选得到的高产菌株在 $50 \mathrm{~L}$ 生物反应器中不同糖浓度发酵生 产柠檬酸的特性, 最终优化出适合于工业化生产柠檬酸的发酵工艺。

研究方法:（1）利用淀粉酶对粉碎后的玉米进行液化, 然后过滤, 最终得上清液; (2) 以 $50 \mathrm{~L}$ 生物反 应器作为发酵设备, 对篮选得到的高产柠檬酸菌株进行扩大培养; (3) 通过测定不同培养 时期中积累的柠檬酸含量和剩余的残总糖，最终优化出高效率生产柠檬酸的发酵工艺。

重要结论: 以不同糖浓度的液化玉米粉上清液作为碳源, 突变菌株 H4002 能积累 177.7 196.0 g/L 的柠檬 酸, 效率能达到 2.96 3.27 g/(L·h), 尤其当糖浓度为 $210 \mathrm{~g} / \mathrm{L}, \mathrm{H} 4002$ 菌株表现出最佳的柠檬 酸生产水平, 如柠檬酸积累 $187.5 \mathrm{~g} / \mathrm{L}$, 生产效率达 $3.13 \mathrm{~g} /(\mathrm{L} \cdot \mathrm{h})$ 。上述结果说明了突变菌株 H4002 拥有快速生产柠檬酸的能力。

关键词组：突变；柠檬酸生产；玉米粉液化液；黑曲霉 